\title{
Parental Absence Accompanies Worse Academic Achievements: Evidence Based upon a Sample of Left-Behind Children in Rural China
}

\author{
Mingchen $\mathrm{Fu}^{1}$, Wenjin Vikki $\mathrm{Bo}^{2}$, Yan Xue ${ }^{3 *}$ and Ti-Fei Yuan ${ }^{3,4,5,6 *}$ \\ ${ }^{1}$ School of Education Science, Nanjing Normal University, Nanjing, China, ${ }^{2}$ Teaching \& Learning Centre, Singapore University \\ of Social Sciences, Singapore, Singapore, ${ }^{3}$ School of Psychology, Naniing Normal University, Nanjing, China, ${ }^{4}$ Shanghai Key \\ Laboratory of Psychotic Disorders, Shanghai Mental Health Center, Shanghai Jiao Tong University School of Medicine, \\ Shanghai, China, ${ }^{5}$ Co-innovation Center of Neuroregeneration, Nantong University, Nantong, China, ${ }^{6}$ State Key Laboratory \\ of Brain and Cognitive Sciences, The University of Hong Kong, Pokfulam, Hong Kong
}

OPEN ACCESS

Edited by:

Puri Checa,

University of Granada, Spain

Reviewed by:

Ma Hai-lin,

Tibet University, China Liang Zhang,

Chinese Academy of Sciences, China

*Correspondence:

Yan Xue

xueyanshuilan@gmail.com;

Ti-Fei Yuan

ytf0707@126.com

Specialty section:

This article was submitted to Educational Psychology,

a section of the journal

Frontiers in Education

Received: 28 April 2017

Accepted: 13 July 2017

Published: 08 August 2017

Citation:

Fu M, Bo W, Xue Y and Yuan T-F (2017) Parental Absence Accompanies Worse Academic Achievements: Evidence Based upon a Sample of Left-Behind Children in Rural China.

Front. Educ. 2:38.

doi: 10.3389/feduc.2017.00038
In China, with the rapid urbanization and large amount of labor force migrating from rural-to-urban areas, an enormous number of children living in rural China are in the absence of parental care. The objective of the study was to investigate the academic performance of left-behind children under various statuses of parental absence. We investigated 3,076 children (1,761 non-left-behind and 1,315 left-behind) regarding their academic achievement in different subjects. We found that children with different status of parental absence would perform differently on Chinese, mathematics, and English learning. In addition, left-behind children would be significantly more likely to get low scores in academic examinations as compared with non-left-behind children. Strengths and limitations of the study are discussed.

Keywords: left-behind children, academic achievement, parental absence, parental involvement, rural education in China

With China's rapid urbanization, an increasing amount of labor force has been migrating from rural to urban areas for job opportunities in recent decades. According to the data revealed from China's national census, the number of rural-to-urban migrant labors in 2010 was 220 million and increased to 245 million in 2013 (National Bureau of Statistics of China, 2011, 2014). Due to the large-scale rural-to-urban migration of labors, an enormous number of children living in rural China are in the absence of parental care. The term of left-behind children refers to such group of children, who live in their original residence with one or both parents migrating to other places for work and, hence, have not being living with parents for 6 months or longer time (Zhou and Duan, 2005; Guo et al., 2012). Based on China's national census data in 2010, China Women's Federation (2008) claimed that the number of left-behind children in China should be more than 61 million, which accounted for $37.7 \%$ of the children living in rural China and $21.9 \%$ of all the children in China.

In recent years, researchers began to pay attention to the psychological status of left-behind children in China, as they live under the pressure of parental absence. Previous studies have shown that as compared with their non-left-behind peers, left-behind children were more likely to suffer from a high level of loneliness, life dissatisfaction, and unhappiness (Jia and Tian, 2010; Jordan and Graham, 2012; Su et al., 2013). However, there has been a lack of study exploring the influence of parental absence on children's academic performance among the left-behind children.

Parenting has been demonstrated to play an essential role in children's academic performance in a number of ways. Prior research indicated that parents' education attainment, attitudes, parental 
aspiration, parent-children interaction, and so forth could considerably contribute to children's academic performance (e.g., Sudhir and Sailo, 1989; Bean et al., 2003; Henry et al., 2008). Particularly, a number of studies showed that parents' engagement in children's school or home lives were positively associated with children's academic performance (Reynolds, 1992; Henry et al., 2008). Furthermore, low-level engagement or parents' neglect on children could lead to academic underachievement (Radziszewska et al., 1996; Boon, 2007). Therefore, it is reasonable to assume that the absence of parents may be associated with the impaired academic performance of children.

Furthermore, some previous studies that compared the academic performance of children in disrupted families with those in intact families have shed more light on the relationship between parental absence and children's academic performance. These studies demonstrated that children in divorced single-parent families performed significantly worse in academic activities than those living with both (Cherian, 1989; Sun and Li, 2011). It was claimed that the relatively low academic achievement among children in disrupted family was most likely due to the lack of access to parents and parental resources (Jeynes, 2005).

Therefore, considering the special parenting condition of the left-behind children, it is necessary to better understand their academic performance. With a sample consisting of both left-behind children and non-left-behind children (children living with both parents) in China, this study examined the association between children's status of parental absence and their academic performance in Chinese, English, and mathematics tests, respectively. Moreover, literature suggests that children who have experienced a history of academic underachievement are more likely to show negative individual outcomes, such as emotional disorder, school dropout, and career development difficulties (e.g., Mandel and Marcus, 1988; Baker, 2004; Hwang et al., 2014). Thus, this study also investigated the association of children's status of parental absence and their likelihood of experiencing academic underachievement in schools. Two hypotheses were made as follows:

1. Children with different types of parental absence would perform differently on Chinese, mathematics, and English learning. Specifically, non-left-behind children would achieve statistically higher scores on Chinese, mathematics, and English tests than children living with only one parent; children with only one parent present would achieve statistically higher scores on Chinese, mathematics, and English tests than those parents are both absent.

2. Left-behind children would be at significantly more likely to get low scores (scores lower than 50th or 75th percentile) in academic examinations as compared with non-left-behind children.

\section{METHODOLOGY}

\section{Participants}

Three thousand and seventy-six children from nine primary schools and three secondary schools participated in the study. All the 12 schools enrolled students majorly from rural areas in
Jiangsu Province in China, and students in each school comprised both left-behind and non-left-behind children. The age of children who participated in the study varied from 9 to 17 years old, including $10.1 \%$ in Grade 3, 20.6\% in Grade 4, 23.4\% in Grade 5, $20.3 \%$ in Grade 6, 8.2\% in Grade 7, $13.0 \%$ in Grade 8, and 3.4\% in Grade 9. Furthermore, $52.9 \%$ of the participants were females and $47.1 \%$ were males. Among the participants, there were 1,761 non-left-behind children and 1,315 left-behind children-which consisted of 659 living with mother only (the group of father absence), 91 living with father only (the group of mother absence), and 565 whose both parents were absent. Ethical approval for the study was achieved from the ethics committee of Nanjing Normal University. Participation of the study was entirely voluntary and consents were obtained from children's parents before the children were enrolled in our study.

\section{Measures}

Questionnaires were administered to the students to collect their demographic information and the status of parental absence. Consents were obtained from the students' parents before the survey was conducted. Demographic information collected by questionnaire included age, grade, sex, socioeconomic status (father's education attainment, mother's education attainment, and family income), and sibling status. The question below asked the participants about their status of parental presence.

In the recent 6 months, have you being living with your parents?

A. I have being living with both my mom and dad;

B. I have being living with my mom while my dad is not at home;

C. I have being living with my dad while my mom is not at home;

D. Both my mom and dad don't live with me.

According to the participants' self-report of this question, they were categorized into groups of non-left-behind, father absence, mother absence, and both-parents absence. Besides, indicators of participants' academic performance were their scores in the final examination of Chinese, mathematics, and English courses in school. The scores were directly achieved from schoolteachers and matched with the children's questionnaire by student ID number or name.

\section{Data Analysis}

First, considering that the final examinations in different schools or grades were different, we standardized all the test scores to eliminate the potential impact of schools and grades on the academic scores. We standardized the scores within score distribution of the specific school and grade a student studied in. All the subsequent analyses utilized the standardized scores as the children's test scores. Second, ANOVA test was performed to compare the academic performance across children of different types of parental absence, concerning their learning in academic disciplines of Chinese, mathematics, and English, respectively. Post hoc analysis with Bonferroni correction (Abdi, 2007) was utilized to further examine the difference on academic scores between any two groups of children with different status parental absence. Third, binary logistic regression analyses with enter method were performed to 
test the association of the status of parental absence with scores lower than 50th and 75th percentile in Chinese, mathematics, and English tests, respectively (Hosmer et al., 2013). All data analyses were carried out in SPSS 19.

TABLE 1 | Descriptive statistics of the test scores (standardized) of children with different status of parental absence.

\begin{tabular}{|c|c|c|c|c|c|c|}
\hline & \multicolumn{2}{|c|}{$\begin{array}{c}\text { Chinese } \\
\text { test }\end{array}$} & \multicolumn{2}{|c|}{$\begin{array}{c}\text { Mathematics } \\
\text { test }\end{array}$} & \multicolumn{2}{|c|}{$\begin{array}{c}\text { English } \\
\text { test }\end{array}$} \\
\hline & $\mathbf{M}$ & SD & $\mathbf{M}$ & SD & $\mathbf{M}$ & SD \\
\hline Non-left-behind & 0.017 & 0.927 & 0.027 & 0.978 & 0.056 & 0.972 \\
\hline Father absence & -0.006 & 0.952 & 0.029 & 0.968 & 0.014 & 0.984 \\
\hline Mother absence & -0.213 & 0.885 & -0.347 & 1.218 & -0.298 & 1.051 \\
\hline Both-parents absence & 0.040 & 0.870 & 0.012 & 0.960 & -0.041 & 0.987 \\
\hline
\end{tabular}

\section{RESULTS}

To begin with, we conducted descriptive statistics concerning the distribution of the test scores of children with different status of parental absence (see Table $\mathbf{1}$ and Figure 1). To compare the test scores between different groups of children further, through ANOVA test, we found that children's performance in mathematics $\left(F=4.22, p=0.005\right.$, partial $\left.\eta^{2}=0.01\right)$ and English $(F=4.57$, $p=0.003$, partial $\left.\eta^{2}=0.01\right)$ tests were statistically different across children with different status of parental absence. However, there was no difference among the four left-behind groups concerning their performance in Chinese tests $(F=2.04, p=0.106$, partial $\eta^{2}=0.00$ ). In post hoc tests, we found that the groups of children whose mother were absent in their lives performed significantly poorer than other groups in both mathematics and English tests. Specifically, with regard to mathematics scores, the scores of the
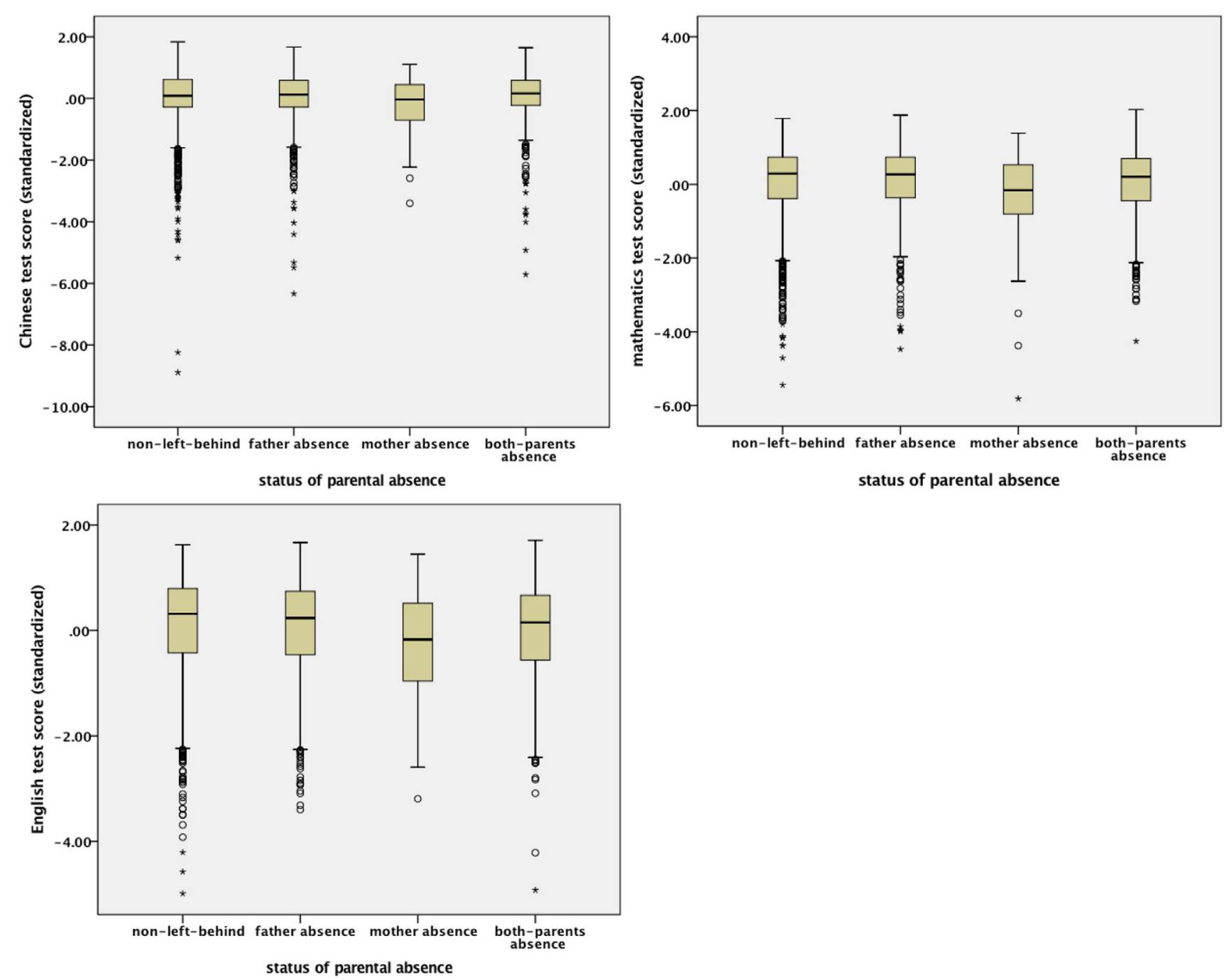

FIGURE 1 | Statistical distribution of test scores (standardized) of children with different status of parental absence. 
mother-absence group $\left(\mathrm{M}_{\text {standardized score }}=-0.347\right)$ were significantly lower than that of the non-left-behind group $\left(\mathrm{M}_{\text {standardized }}\right.$ score $=0.027, p<0.01)$, the father-absence group $\left(\mathrm{M}_{\text {standardized }}\right.$ score $=0.029)$, and the both-parents-absence group $\left(\mathrm{M}_{\text {standardized }}\right.$ score $=0.012, p<0.01$ ), respectively. In terms of English scores, the scores of the mother-absence group $\left(\mathrm{M}_{\text {standardized score }}=-0.298\right.$, $p<0.01)$ were significantly lower than that of the non-left-behind group $\left(\mathrm{M}_{\text {standardized score }}=0.056, p<0.01\right)$ and the father-absence group $\left(\mathrm{M}_{\text {standardized score }}=0.014, p<0.05\right)$, respectively. With regard to father's absence, nevertheless, we found that there was no significant between father-absence group $\left(\mathrm{M}_{\text {standardized mathematics }}\right.$ score $\left.=0.029, \mathrm{M}_{\text {standardized English score }}=0.014\right)$ and non-left-behind group $\left(M_{\text {standardized mathematics score }}=0.027, M_{\text {standardized English score }}=0.056\right)$.

We further examined the association of the status of parental absence with of the likelihood of getting low scores in the tests of Chinese, mathematics, and English, respectively. To eliminate the effect of demographic factors, we controlled the effect of demographic factors in each logistic regression model. Take the regressions on 50th percentile and lower scores in Chinese tests for example. First, as shown in Model 1 (see Table 2), we put all demographic factors into a logistic regression model to predict 50th percentile and lower scores in Chinese tests. By the model, we identified that age, father's education attainment, and income were significantly associated with 50th percentile and lower scores in Chinese tests. Therefore, these three factors were controlled in Model 2 , which was established for investigating the association of the status of parental absence with 50th percentile and lower scores in Chinese tests. Besides, the group of non-left-behind children was set as reference in all models.

The logistic regression models for predicting lower scores in Chinese, mathematics, and English tests are presented in Tables 2-4, respectively. As hypothesized, the status of both-parents absence was significantly associated with 75 th percentile and lower scores in Chinese tests, 50th percentile and lower scores in mathematics tests. The association of the status of both-parents absence with 75th percentile and lower scores in mathematics tests was also marginally significant. Specifically, in comparison with children of no-parent-left, children of both-parents absence were 1.815 times more likely to get 75th percentile or lower scores in Chinese tests, 1.789 times more likely to get 50th percentile or lower scores in mathematics tests, 1.603 times more likely to get 75 th percentile or lower scores in mathematics tests. However, opposite to what was expected, as compared with the non-left-behind children, those with father absence showed significantly lower risk of

TABLE 2 | Logistic regression models for predicting lower scores in Chinese tests.

\begin{tabular}{|c|c|c|c|c|c|c|c|c|c|c|}
\hline \multirow{3}{*}{$\begin{array}{l}\text { Variables } \\
\text { Grade }\end{array}$} & \multicolumn{5}{|c|}{ 50th percentile and lower } & \multicolumn{5}{|c|}{ 75th percentile and lower } \\
\hline & \multirow[b]{2}{*}{ Model 1} & \multirow{2}{*}{$\begin{array}{c}\text { OR } \\
0.962\end{array}$} & \multirow{2}{*}{$\begin{array}{c}\text { Sig. } \\
0.550\end{array}$} & \multicolumn{2}{|c|}{$95 \% \mathrm{Cl}$ of OR } & \multirow[b]{2}{*}{ Model 3} & \multirow{2}{*}{$\begin{array}{c}\text { OR } \\
1.073\end{array}$} & \multirow{2}{*}{$\begin{array}{c}\text { Sig. } \\
0.316\end{array}$} & \multicolumn{2}{|c|}{$95 \% \mathrm{Cl}$ of OR } \\
\hline & & & & 0.849 & 1.091 & & & & 0.935 & 1.232 \\
\hline Sex & & 1.076 & 0.352 & 0.922 & 1.255 & & 1.163 & 0.081 & 0.982 & 1.378 \\
\hline Age & & 1.134 & 0.038 & 1.007 & 1.276 & & 1.040 & 0.555 & 0.913 & 1.184 \\
\hline Sibling & & 1.027 & 0.554 & 0.941 & 1.120 & & 1.042 & 0.395 & 0.947 & 1.146 \\
\hline Father's education attainment & & 0.758 & 0.000 & 0.679 & 0.845 & & 0.717 & 0.000 & 0.634 & 0.811 \\
\hline Mother's education attainment & & 1.081 & 0.148 & 0.973 & 1.201 & & 1.107 & 0.086 & 0.986 & 1.244 \\
\hline Income & & 0.827 & 0.011 & 0.714 & 0.957 & & 0.963 & 0.643 & 0.820 & 1.131 \\
\hline Non-left-behind (reference) & Model 2 & - & - & - & - & Model 4 & - & - & - & - \\
\hline Father absence & & 0.788 & 0.023 & 0.641 & 0.967 & & 0.933 & 0.520 & 0.754 & 1.153 \\
\hline Mother absence & & 0.841 & 0.163 & 0.659 & 1.073 & & 0.855 & 0.227 & 0.663 & 1.103 \\
\hline Both-parents absence & & 1.421 & 0.155 & 0.875 & 2.306 & & 1.815 & 0.011 & 1.145 & 2.877 \\
\hline
\end{tabular}

Demographic factors controlled in Model 2 were age, father's education attainment, and income; in Model 4 was father's education attainment.

Significant findings are marked in bold.

TABLE 3 | Logistic regression models for predicting lower scores in mathematics tests.

\begin{tabular}{|c|c|c|c|c|c|c|c|c|c|c|}
\hline \multirow{3}{*}{$\begin{array}{l}\text { Variables } \\
\text { Grade }\end{array}$} & \multicolumn{5}{|c|}{ 50th percentile and lower } & \multicolumn{5}{|c|}{ 75th percentile and lower } \\
\hline & \multirow[b]{2}{*}{ Model 5} & \multirow{2}{*}{$\begin{array}{c}\text { OR } \\
0.907\end{array}$} & \multirow{2}{*}{$\begin{array}{c}\text { Sig. } \\
0.122\end{array}$} & \multicolumn{2}{|c|}{$95 \% \mathrm{Cl}$ of OR } & \multirow[b]{2}{*}{ Model 7} & \multirow{2}{*}{$\frac{\text { OR }}{1.108}$} & \multirow{2}{*}{$\begin{array}{l}\text { Sig. } \\
0.167\end{array}$} & \multicolumn{2}{|c|}{$95 \% \mathrm{Cl}$ of OR } \\
\hline & & & & 0.801 & 1.027 & & & & 0.958 & 1.281 \\
\hline Sex & & 1.034 & 0.666 & 0.888 & 1.204 & & 1.187 & 0.060 & 0.993 & 1.418 \\
\hline Age & & 1.180 & 0.006 & 1.049 & 1.327 & & 1.028 & 0.688 & 0.898 & 1.178 \\
\hline Sibling & & 1.048 & 0.285 & 0.962 & 1.142 & & 1.064 & 0.223 & 0.963 & 1.176 \\
\hline Father's education attainment & & 0.784 & 0.000 & 0.705 & 0.872 & & 0.726 & 0.000 & 0.638 & 0.826 \\
\hline Mother's education attainment & & 1.083 & 0.130 & 0.977 & 1.202 & & 1.157 & 0.018 & 1.025 & 1.307 \\
\hline Income & & 0.834 & 0.014 & 0.722 & 0.964 & & 1.007 & 0.936 & 0.850 & 1.193 \\
\hline Non-left-behind (reference) & Model 6 & - & - & - & - & Model 8 & - & - & - & - \\
\hline Father absence & & 0.854 & 0.127 & 0.696 & 1.046 & & 1.003 & 0.979 & 0.800 & 1.258 \\
\hline Mother absence & & 0.962 & 0.751 & 0.756 & 1.224 & & 0.940 & 0.652 & 0.717 & 1.232 \\
\hline Both-parents absence & & 1.789 & 0.022 & 1.086 & 2.948 & & 1.603 & 0.056 & 0.988 & 2.602 \\
\hline
\end{tabular}

Demographic factors controlled in Model 6 were age, father's education attainment, and income; in Model 8 were father's education attainment and mother's education attainment. Significant findings are marked in bold. 
TABLE 4 | Logistic regression models for predicting lower scores in English tests.

\begin{tabular}{|c|c|c|c|c|c|c|c|c|c|c|}
\hline \multirow{3}{*}{$\begin{array}{l}\text { Variables } \\
\text { Sibling }\end{array}$} & \multicolumn{5}{|c|}{ 50th percentile and lower } & \multicolumn{5}{|c|}{ 75th percentile and lower } \\
\hline & \multirow[b]{2}{*}{ Model 9} & \multirow{2}{*}{$\frac{\text { OR }}{1.119}$} & \multirow{2}{*}{$\begin{array}{c}\text { Sig. } \\
0.011\end{array}$} & \multicolumn{2}{|c|}{$95 \% \mathrm{Cl}$ of OR } & \multirow[b]{2}{*}{ Model 11} & \multirow{2}{*}{$\begin{array}{c}\text { OR } \\
1.009\end{array}$} & \multirow{2}{*}{$\begin{array}{l}\text { Sig. } \\
0.846\end{array}$} & \multicolumn{2}{|c|}{$95 \% \mathrm{Cl}$ of OR } \\
\hline & & & & 1.026 & 1.221 & & & & 0.918 & 1.110 \\
\hline Father's education attainment & & 0.751 & 0.000 & 0.673 & 0.837 & & 0.737 & 0.000 & 0.651 & 0.834 \\
\hline Mother's education attainment & & 1.116 & 0.041 & 1.004 & 1.240 & & 1.019 & 0.753 & 0.906 & 1.146 \\
\hline Sex & & 1.736 & 0.000 & 1.487 & 2.026 & & 2.113 & 0.000 & 1.776 & 2.515 \\
\hline Age & & 1.194 & 0.004 & 1.060 & 1.345 & & 1.233 & 0.001 & 1.084 & 1.404 \\
\hline Grade & & 0.857 & 0.017 & 0.756 & 0.973 & & 0.899 & 0.128 & 0.783 & 1.031 \\
\hline Income & & 0.920 & 0.265 & 0.795 & 1.065 & & 0.915 & 0.281 & 0.778 & 1.076 \\
\hline Non-left-behind (reference) & Model 10 & - & - & - & - & Model 12 & - & - & - & - \\
\hline Father absence & & 0.779 & 0.018 & 0.633 & 0.957 & & 0.888 & 0.301 & 0.710 & 1.112 \\
\hline Mother absence & & 0.850 & 0.193 & 0.665 & 1.086 & & 0.932 & 0.603 & 0.714 & 1.216 \\
\hline Both-parents-absence & & 0.982 & 0.942 & 0.596 & 1.618 & & 1.448 & 0.151 & 0.873 & 2.400 \\
\hline
\end{tabular}

Demographic factors controlled in Model 10 were sibling status, father's education attainment, mother's education attainment, sex, age, and grade; in Model 12 were sibling status, father's education attainment, sex, and age.

Significant findings are marked in bold.

getting 50th percentile or lower scores in both Chinese and English tests.

\section{DISCUSSIONS}

Findings of the study indicated the significant associations between children's status of parental absence and their academic performance. According to the findings, children at different status of parental absence performed differently in academic tests. Furthermore, children with both-parents absence were more likely to academically underachieve as compared with their peers.

To begin with, consistent with Hypothesis 1, the test scores of mathematics and English were significantly distinguished across children with different status of parental absence. Through post hoc analysis, it was found that the mother-absence group performed the worst regarding their scores in the three academic disciplines as compared with the groups of children with other status of parental absence (e.g., father absence, both-parents absence). Children with mother absence showed significantly lower scores than non-left-behind children in both mathematics and English tests. Moreover, the mother-absence group also performed significantly worse than father-absence group in English and mathematics tests. Nevertheless, the expected distinctions between non-left-behind children and other groups except children of mother absence were not found in either test of the three academic disciplines. Second, Hypothesis 2 was also essentially supported by findings of this study. In comparison with non-leftbehind children, the both-parents-absence group was statistically more likely to academically underachieve regarding their performance in both Chinese and mathematics tests. A number of studies have evidenced that the absence of one parent resulted in higher risk of children's underachievement (e.g., Riala et al., 2003; Sun and Li, 2011). However, there has been no previous evidence on children's academic performance concerning the situation of both parents being absent. Therefore, based on a large sample of left-behind children, this study systematically compared the academic performance across children with different status of parental absence and provided evidence for the relations of both parents with children's academic performance.
It is noted that results concerning both hypotheses consistently showed a weak association of father's presence with children's academic performance. Some previous studies, also having lent support to this study, showed that the presence of father played a weak role in benefiting children's academic achievement. Shilling and Lynch (1985) found among a group of eighth grade children that those who lived only with mothers obtained significantly higher academic achievement than those who lived only with fathers. Similar finding was also reported by another study that was conducted among children living with single-female-parent family. This study demonstrated that the absence of father did not attenuate children's academic progress (Watts and Watts, 1991).

Why is the association between father's presence and children's academic performance so weak? One may wonder that children benefit very little from father's involvement in their lives. However, evidence from literature suggests that father's parental involvement actually has significant positive contributions to children's cognitive and mental health development. A meta-analysis conducted by Jeynes (2015) demonstrated the statistically significant association between father's parental involvement and children's educational outcomes (academic achievement, psychological outcome, cognitive ability, etc.). Furthermore, another meta-analysis conducted in 2015 by Kim and Hill (2015) indicated that the role of parental involvement of fathers in children's academic performance was just as strong as that of mothers. Nevertheless, researchers realized that even though father's parental involvement played a crucial role in children's psychological development, "their behavior falls short of ideal" (p. 976; Atkinson and Blackwelder, 1993). Empirical research conducted in different cultures consistently reported the low-level involvement of fathers in caring or educating children (e.g., Hossain and Anziano, 2008; Sanders et al., 2010; Huang et al., 2012). Moreover, Kim and Hill's (Kim and Hill, 2015) metaanalysis also found that the mean-level of parental involvement of mothers was significantly higher than that of fathers. Therefore, the weak association of father's presence with children' academic achievement is likely due to the lack of effective parental fathers in family. 
An unexpected finding that we found further was that children with mother absence performed even poorer in academic tests than children with both-parents left. A possible explanation is that children with both-parents absence may receive more care by other relatives or teachers than those who live with fathers. Besides, previous research showed that inappropriate parenting styles would contribute to low academic achievement of children (e.g., Melby and Conger, 1996; Boon, 2007). Sanders et al. (2010) found in a survey among 933 fathers in Australia that approximately half of the fathers had used one or more coercive parenting strategies, such as hitting the children and yelling to the children. The study also demonstrated that father's hitting was statistically associated with children's behavioral difficulties. Therefore, both the low level of parental involvement and inappropriate parenting behavior of fathers are likely to be the reasons regarding the saliently lower academic achievement of children with mother absence as compared with other groups of children.

Furthermore, we found in our study that the results on the relationships between academic performance and the status of parental absence were distinct across the three academic disciplines. Regarding the findings for examining Hypothesis 1 , the distinction of academic performance was only shown in mathematics and English, but not in Chinese. In respect to the findings for testing Hypothesis 2, both-parents-absence group were saliently more likely to suffer from underachievement in only mathematics and Chinese tests but not in English. Jeynes (2005) investigated the association of parental involvement and family structure with children's academic performance in five different disciplines, including reading, mathematics, social studies, science, and composite. It was found that even though parental involvement and family structure were, respectively, associated with all academic performances, the extent of associations were different across academic disciplines. However, as the correlation between parental involvement and academic performance was typically examined with a sum score of academic achievement (e.g., Henry et al., 2008; Alvarez-Valdivia et al., 2013), there have been very few studies exploring the correlation within different disciplines. Findings of this study, consistent with Jeynes' (Jeynes, 2005) finding, implied that it is necessary to investigate the association of parental involvement or parental presence with academic performance concerning different specific academic disciplines.

\section{CONCLUSION, IMPLICATIONS, AND LIMITATIONS}

With a large sample of left-behind and non-left-behind children, our study was the first study that that systematically compared the academic achievement of children across different types of parental absence (mother absence, father absence, both-parents absence, no parental absence). It was found that the average achievements of the children with mother absence were particularly lower as compared with non-left-behind children and the children with father absence regarding their scores in mathematics and English tests. Furthermore, the children with both-parents absence were considerably more likely to underachieve in both Chinese and mathematics learning in comparison with their peers.
Left-behind children made up a huge group in rural areas of China. From a practical perspective, findings of our study showed implications concerning the education and parenting for the left-behind children. Considering the relatively low academic achievement and the high likelihood of underachievement of the left-behind children, schoolteachers are supposed to pay more attention to the cognitive development of the left-behind children. Moreover, given the potentially low-level involvement and inappropriate parenting behaviors of the carers (e.g., one of the parents, other relative) of the left-behind children, schoolteachers are expected to contact the families of these children regularly through phone or home visit. Furthermore, in a theoretical sense, this study has implications for future research in the field of parenting. First, the study served as one more evidence that father's presence did not benefit, or even possibly undermined children's academic achievement. This finding implies a need for more emphasis on the research of fathering than simply parenting. Second, findings of the study showed the status of parental absence were associated with children's academic performance differently across different academic disciplines. Therefore, it implies that the association of parental involvement or family structure with academic performance should not only be studied with a summarized score of academic achievement but also within specific academic disciplines.

Finally, as a limitation of the study, it should be noted that the specific living status of the children with both-parents absence was unclear. The children are likely to have been living with their grandparents, other relatives, or living at school under the guardian of teachers. Even though it was found that the children with both-parents absence were at the highest risk of underachievement, a deeper understanding of the specific living status of the children with both-parents absence is needed in future studies.

\section{ETHICS STATEMENT}

This study was carried out in accordance with the recommendations of gridlines by Ethics Committee of Nanjing Normal University, China with written informed consent from all subjects. All subjects gave written informed consent in accordance with the Declaration of Helsinki. The protocol was approved by the Ethics Committee of Nanjing Normal University, China.

\section{AUTHOR CONTRIBUTIONS}

MF designed the specific study, did data analyses, and wrote the manuscript; WB helped designed the study and helped polished the writing of the article; YX was in charge of a project of research on left-behind children in rural China (which the study was involved in), provided funding, collected data, and participated in the writing and revision of the article. TY helped design the study and contact the participants.

\section{FUNDING}

The study is funded by Social Science Research Fund Project in Jiangsu Province, China, 2015 (Grant No. 15JYB016) to YX. 


\section{REFERENCES}

Abdi, H. (2007). "Bonferroni and Šidák corrections for multiple comparisons," in Encyclopedia of Measurement and Statistics, ed. N. J. Salkind (Thousand Oaks, CA: SAGE), 103-107.

Alvarez-Valdivia, I., Chavez, K. L., Schneider, B. H., Roberts, J. S., Becalli-Puerta, L., Pérez-Luján, D., et al. (2013). Parental involvement and the academic achievement and social functioning of Cuban school children. Sch. Psychol. Int. 34, 313-329. doi:10.1177/0143034312465794

Atkinson, M. P., and Blackwelder, S. P. (1993). Fathering in the 20th century. J. Marriage Fam. 55, 975-986. doi:10.2307/352777

Baker, J. A. (2004). "Depression and suicidal ideation among academically gifted adolescents," in Social/Emotional Issues, Underachievement, and Counseling of Gifted and Talented Students, ed. S. M. Reis (Thousand Oaks, CA: Corwin), 21-30.

Bean, R. A., Bush, K. R., McKenry, P. C., and Wilson, S. M. (2003). The impact of parental support, behavioral control, and psychological control on the academic achievement and self-esteem of African American and European American adolescents. J. Adolesc. Res. 18, 523-541. doi:10.1177/0743558403255070

Boon, H. J. (2007). Low- and high-achieving Australian secondary school students: their parenting, motivations and academic achievement. Aust. Psychol. 42, 212-225. doi:10.1080/00050060701405584

Cherian, V. I. (1989). Academic achievement of children of divorced parents. Psychol. Rep. 64, 355-358. doi:10.2466/pr0.1989.64.2.355

China Women's Federation. (2008). National Survey of Left-Behind Children in Rural Areas. Available at: http://www.china.com.cn/zhibo/2008-02/27/content_10180165.htm

Guo, J., Chen, L., Wang, X., Liu, Y., Chui, C. H. K., He, H., et al. (2012). The relationship between Internet addiction and depression among migrant children and left-behind children in China. Cyberpsychol. Behav. Soc. Netw. 15, 585-590. doi:10.1089/cyber.2012.0261

Henry, C. S., Merten, M. J., Plunkett, S. W., and Sands, T. (2008). Neighborhood, parenting, and adolescent factors and academic achievement in Latino adolescents from immigrant families. Fam. Relat. 57, 579-590. doi:10.1111/j.1741-3729.2008.00524.x

Hosmer, D. W. Jr., Lemeshow, S., and Sturdivant, R. X. (2013). Applied Logistic Regression. Hoboken, NJ: John Wiley \& Sons.

Hossain, Z., and Anziano, M. C. (2008). Mothers' and fathers' involvement with school-age children's care and academic activities in Navajo Indian families. Cultur. Divers. Ethnic Minor. Psychol. 14, 109-117. doi:10.1037/1099-9809.14.2.109

Huang, Y., Chen, S., and Tsai, S. (2012). Father's experiences of involvement in the daily care of their child with developmental disability in a Chinese context. J. Clin. Nurs. 21, 3287-3296. doi:10.1111/j.1365-2702.2012.04142.X

Hwang, M. H., Lee, D., Lim, H. J., Seon, H. Y., Hutchison, B., and Pope, M. (2014). Academic underachievement and recovery: student perspectives on effective career interventions. Career Dev. Q. 62, 81-94. doi:10.1002/j.2161-0045.2014.00072.x

Jeynes, W. H. (2005). Effects of parental involvement and family structure on the academic achievement of adolescents. Marriage Fam. Rev. 37, 99-116. doi:10.1300/J002v37n03_06

Jeynes, W. H. (2015). A meta-analysis the relationship between father involvement and student academic achievement. Urban Educ. 50, 387-423. doi:10.1177/ 0042085914525789

Jia, Z., and Tian, W. (2010). Loneliness of left-behind children: a cross-sectional survey in a sample of rural China. Child Care Health Dev. 36, 812-817. doi:10.1111/ j.1365-2214.2010.01110.x

Jordan, L. P., and Graham, E. (2012). Resilience and well-being among children of migrant parents in South-East Asia. Child Dev. 83, 1672-1688. doi:10.1111/ j.1467-8624.2012.01810.x
Kim, S. W., and Hill, N. E. (2015). Including fathers in the picture: a meta-analysis of parental involvement and students' academic achievement. J. Educ. Psychol. 107, 919-934. doi:10.1037/edu0000023

Mandel, H. P., and Marcus, S. I. (1988). The Psychology of Underachievement: Differential Diagnosis and Differential Treatment. New York, NY: Wiley.

Melby, J. N., and Conger, R. D. (1996). Parental behaviors and adolescent academic performance: a longitudinal analysis. J. Res. Adolesc. 6, 113-137.

National Bureau of Statistics of China. (2011). Demographic Statistics from the 2010 Census. Available at: http:///uploads/soft/1_110531163254.pdf

National Bureau of Statistics of China. (2014). Demographic Statistics from the 2013 Census. Available at: http://www.stats.gov.cn/tjgz/tjdt/201407/ t20140707_577438.html

Radziszewska, B., Richardson, J. L., Dent, C. W., and Flay, B. R. (1996). Parenting style and adolescent depressive symptoms, smoking, and academic achievement: ethnic, gender, and SES differences. J. Behav. Med. 19, 289-305. doi:10.1007/ BF01857770

Reynolds, A. J. (1992). Comparing measures of parental involvement and their effects on academic achievement. Early Child. Res. Q. 7, 441-462. doi:10.1016/0885-2006(92)90031-S

Riala, K., Isohanni, I., Jokelainen, J., Jones, P. B., and Isohanni, M. (2003). The relationship between childhood family background and educational performance, with special reference to single-parent families: a longitudinal study. Soc. Psychol. Educ. 6, 349-365. doi:10.1023/A:1025608401292

Sanders, M. R., Dittman, C. K., Keown, L. J., Farruggia, S., and Rose, D. (2010). What are the parenting experiences of fathers? The use of household survey data to inform decisions about the delivery of evidence-based parenting interventions to fathers. Child Psychiatry Hum. Dev. 41, 562-581. doi:10.1007/ s10578-010-0188-Z

Shilling, F., and Lynch, P. D. (1985). Father versus mother custody and academic achievement of eighth grade children. J. Res. Dev. Educ. 18, 7-11.

Su, S., Li, X., Lin, D., Xu, X., and Zhu, M. (2013). Psychological adjustment among left-behind children in rural China: the role of parental migration and parent-child communication. Child Care Health Dev. 39, 162-170. doi:10.1111/j.1365-2214.2012.01400.x

Sudhir, M. A., and Sailo, L. (1989). Parent child interaction and academic achievement among secondary school students in Aizawl. Indian J. Psychometry Educ. 20, 19-28.

Sun, Y., and Li, Y. (2011). Effects of family structure type and stability on children's academic performance trajectories. J. Marriage Fam. 73, 541-556. doi:10.1111/j.1741-3737.2011.00825.x

Watts, D. S., and Watts, K. M. (1991). The impact of female-headed single parent families on academic achievement. J. Divorce Remarriage 17, 97-114. doi:10.1300/J087v17n01_07

Zhou, F. L., and Duan, C. R. (2005). Literature review on studies on left-behind children [in Chinese]. Popul. Res. 29, 29-36. doi:10.3969/j. issn.1000-6087.2005.01.004

Conflict of Interest Statement: The authors declare that the research was conducted in the absence of any commercial or financial relationships that could be construed as a potential conflict of interest.

Copyright (c) $2017 \mathrm{Fu}, \mathrm{Bo}$, Xue and Yuan. This is an open-access article distributed under the terms of the Creative Commons Attribution License (CC BY). The use, distribution or reproduction in other forums is permitted, provided the original author(s) or licensor are credited and that the original publication in this journal is cited, in accordance with accepted academic practice. No use, distribution or reproduction is permitted which does not comply with these terms. 